\title{
Inventário de Estilos Parentais (IEP): um novo instrumento para avaliar as relações entre pais e filhos
}

\author{
Irabela Tissot Antunes Sampaio
}

\author{
Gomide, P. I. C. (2006). Inventário de Estilos Parentais. Modelo teórico: manual de aplicação, apuração e \\ interpretação. Petrópolis: Vozes.
}

Ao falar em relações entre pais e filhos, encontramse na literatura diversos modelos teóricos criados e adaptados por pesquisadores que buscam avaliar como as práticas educativas parentais podem afetar o desenvolvimento dos filhos. Esses modelos podem favorecer o desenvolvimento de trabalhos preventivos, de avaliação, orientação e intervenção. Pais podem otimizar o seu papel parental, e psicólogos e outros profissionais, melhorar sua eficiência no estudo e atendimento das famílias, que constituem um núcleo importantíssimo para a compreensão do ser humano.

É justamente nessa área que se encontra o Modelo de Estilo Parental criado pela professora Paula Inez Cunha Gomide e equipe. O Inventário de Estilos Parentais (IEP), publicado pela Editora Vozes (2006) e favorecido pelo Conselho Federal de Psicologia em julho de 2005, apresenta como certas práticas utilizadas pelos pais na educação dos filhos podem acarretar, por um lado, o desenvolvimento de comportamentos anti-sociais e, por outro, o desenvolvimento de comportamentos pró-sociais de crianças e adolescentes.

O IEP visa auxiliar especialmente profissionais que trabalham com famílias que apresentam risco social, pois permite detectar a quais práticas parentais um indivíduo esteve ou está sujeito, e qual a influência delas no desenvolvimento de comportamentos anti-sociais, como o abuso de substâncias, atos homicidas, infratores, etc. $\mathrm{O}$ instrumento também permite que se visualizem as práticas administradas pelos pais que devem ser modificadas, mantidas ou otimizadas, no caso de busca de orientação, intervenção e encaminhamento à terapia de família, por exemplo. Aqui se incluem as famílias que buscam ajuda no sistema jurídico e demais programas de auxílio mantidos por políticas públicas.

O inventário deriva de um modelo teórico composto por sete práticas educativas, sendo duas consideradas positivas (monitoria positiva e comportamento moral) e cinco negativas (abuso físico, disciplina relaxada, monitoria negativa, negligência e punição inconsistente). No manual de aplicação, as práticas estão descritas e são sustentadas conforme a literatura da área.

Quando se diz que um pai ou uma mãe pratica a monitoria positiva, entende-se que ele tem conhecimento acerca de onde seu filho se encontra, de suas atividades, gostos e preferências. Mediante as práticas que compõem a categoria comportamento moral, os pais ensinam valores como honestidade, empatia e senso de justiça aos filhos, auxiliando-os na discriminação do certo e do errado por meio de modelos positivos.

Quando a punição inconsistente ocorre, os pais educam de acordo com seu humor do momento e não de forma contingente ao comportamento da criança, deixando-as confusas na discriminação dos seus comportamentos. E praticam a negligência quando são ausentes, não se interessam pelos filhos e não efetuam um papel significativo nas suas vidas. Eximindo-se de suas responsabilidades e omitindo-lhes auxílio, podem criar crianças inseguras, agressivas e com baixa auto-estima.

Quando os pais determinam regras e acabam eles mesmos por desrespeitá-las, ou esquecê-las, eles praticam a chamada disciplina relaxada. Por outro lado, quando determinam regras em excesso, fiscalizam em demasia a vida dos filhos e repetem uma ordem diversas vezes, eles utilizam a monitoria negativa (ou supervisão estressante).

Por fim, pais que praticam o abuso físico utilizam práticas corporais lesivas na tentativa de controlar $\mathrm{O}$ comportamento dos filhos, causando dor, machucados ou marcas na pele da criança. $\mathrm{O}$ abuso físico e a negligência mostram-se como os principais desencadeadores de comportamentos anti-sociais de crianças e adolescentes.

Além do construto teórico, o livro explica os passos de elaboração do inventário. Como sua construção foi processual, durante cinco anos várias foram as pesquisas realizadas para sua elaboração. A validação da versão final foi efetuada a partir da aplicação do IEP em 769 jovens pertencentes a dois grupos: $136 \mathrm{em}$ situação de risco (crianças e adolescentes institucionalizados em educandários e lares de vítimas abusadas sexual e fisicamente, e de casas-lar) e 633 estudantes de escolas públicas e particulares. A autora também descreve cinco pesquisas realizadas que colaboraram para a validação do instrumento.

A primeira delas comparou o IEP respondido pelos filhos com um IEP adaptado para os pais. Constatou-se que pais e filhos respondem de forma similar ao instrumento, o que permite que ele seja utilizado tanto com as crianças quanto com seus pais, facilitando a 
obtenção dos dados. A segunda pesquisa realizou entrevistas de profundidade com pais cujos filhos foram considerados "de risco" e "não-risco", gerando dados qualitativos que demonstraram a validade interna do instrumento.

A terceira pesquisa focalizou a categoria "comportamento moral", sendo a mais complicada de se validar nos estudos piloto realizados. Pela comparação dos escores do IEP com os de um questionário sobre comportamento moral, e a análise de discurso obtido em um grupo de debate com pais dos grupos de "risco"e "não-risco", essa categoria pôde ser mais bem adequada ao modelo do IEP.

Para a validação externa do instrumento, o IEP foi correlacionado com os seguintes inventários: Inventário de Habilidades Sociais (IHS), Inventário de Depressão de Beck (CDI) e Inventário de Stress de Lipp (ISL). Constatou-se correlação positiva entre o IEP e o IHS, especificamente com relação ao fator 2 (auto-afirmação na expressão de sentimentos positivos), e negativa entre $O$ IEP e o CDI e ISL. Assim, quanto maior o IEP, maior o índice de habilidades sociais - fator 2, o que permite concluir que os pais que apresentam práticas educativas predominantemente positivas têm mais facilidade de expressar afeto e demonstrar emoções, o que otimiza a qualidade de vida e a harmonia entre as pessoas. Por outro lado, quanto maior o IEP, menores os índices de depressão e estresse, o que indica que pais com práticas educativas predominantemente positivas apresentam menos depressão e estresse, duas variáveis que podem predispor ao comportamento hostil ou indiferente.

A última pesquisa citada refere-se a um programa de intervenção realizado com cinco mães de meninos em conflito com a lei. Por meio das intervenções, em grupo, percebeu-se que as mães praticavam pouca monitoria positiva e utilizavam o abuso físico como forma educativa. Além disso, o grupo mostrou-se como um recurso adequado para que os profissionais possam orientar e intervir com famílias consideradas "de risco".
As práticas que constituem o IEP são avaliadas através de seis (6) questões cada, totalizando 42. As respostas são dadas em uma escala de likert de 3 pontos, em que sempre vale 2 pontos; às vezes, 1 ponto; ou nunca, 0 (zero) ponto. O IEP fornece um escore, o iep (indice de estilo parental), que é resultado da subtração da soma das práticas negativas da soma das positivas.

O índice é um escore bruto que deve ser consultado nas tabelas normativas, em que são apresentados os percentis correspondentes aos valores encontrados. Há duas tabelas, uma referente às práticas maternas e outra às paternas. Encontrando-se o valor percentual, observa-se qual estilo parental é predominante. Essa referência é dada por uma tabela em que os percentis são agrupados nas seguintes categorias: estilo parental ótimo, regular acima da média, regular abaixo da média, e de risco.

O aplicador do IEP pode observar o escore final geral (iep) ou analisar cada prática de forma particular, caso seja mais proveitoso. Ao se interpretar prática por prática, pode-se obter uma melhor visualização de quais devem ser trabalhadas e quais estão adequadas, facilitando o encaminhamento das decisões.

Ao final do livro, anexado, encontra-se o IEP nas suas três versões: a) em que o filho(a) responde em relação ao pai; b) em relação à mãe; e c) auto-aplicação, em que os pais respondem sobre sua forma de educar os filhos. Também está incluída a folha de respostas.

Educar é uma arte. E não é fácil. Avaliar como é realizada, ainda é mais difícil. Esse instrumento poderá auxiliar o profissional a melhor avaliar e intervir em relações de pais e filhos que potencialmente podem desenvolver comportamentos anti-sociais. Também é útil em treinamento de pais, em que pode ser utilizado como medida de avaliação da intervenção. Por fim, ele tem sido utilizado em pesquisas que buscam estabelecer correlações dos estilos parentais com depressão, drogadição, ansiedade, comportamento infrator, habilidades sociais e outras variáveis de interesse da psicologia.

Sobre a autora:

Izabela Tissot Antunes Sampaio é psicóloga formada pela UFPR, mestranda do Programa de Pós-Graduação em Psicologia da UFSC, atualmente estudando a relação entre as práticas educativas parentais, gênero e ordem de nascimento dos filhos. 